\title{
Studies of Chlorpromazine-Induced Enhancement of the Potentials Evoked by Peripheral Stimulation of the Cat Cerebellum
}

\author{
Yukihiko HAGIWARA and Yukiko SUZUKI \\ Department of Pharmacology, Showa College of Pharmaceutical Sciences, \\ 5-1-8. Tsurumaki, Setagaya-ku, Tokyo 154, Japan
}

Accepted March 27, 1987

\begin{abstract}
In the experiments reported here. we investigated effects of CPZ on the amplitude of cerebellar potentials using decerebrated or spinal cat; furthermore. we also examined the effects of microinjecting CPZ. DA or NE into the precerebellar nucle on the amplitude of the cerebellar potentials. 2) Purkinje cell spontaneous discharge was either hardly changed or was depressed by CPZ. 3) CPZ did not change the potentials evoked by peripheral stimulation on the dorsal surface of the spinal cord. 4) CPZ depressed significantly the cerebellar potentials evoked by stimulation of the nucleus reticularis lateralis (LRN) or nucleus olivaris inferior $(I O N)$ in intact. decerebrated and spinal cats. 5) The cerebellar potentials evoked by the peripheral nerve stimulation were increased by microinjection of CPZ into the bilateral LRN but not into the bilateral ION. Microinjection of NE or CPZ into the contralateral LRN hardly influenced the cerebellar evoked potentials. 6) Although electrical stimulation at high frequencies of the ipsilateral LRN depressed significantly the cerebellar evoked potentials; similar stimulation after i.v. pretreatment of CPZ failed to affect them. Microinjection of CPZ into the ipsilateral LRN enhanced the cerebellar evoked potentials, and microinjection of NE or DA depressed them significantly. Furthermore, after pretreatment with $C P Z$, microinjection of DA failed to depress the potentials. 7) We suggest that intravenous CPZ-induced enhancement of the cerebellar potentials may be due to depression of the descending inhibitory mechanism, resulting from CPZ-induced blockage of the catecholamine receptors of the ipsilateral LRN and of the spinal level.
\end{abstract}

The cerebellum is closely connected with the cerebrum, spinal cord and periphery, and influences delicate motor functions. There are many neurotransmitters in the cerebellum such as giutamate, aspartate. GABA and taurine $(1,2)$ as well as the noradrenergic neuron from the nucleus locus coeruleus (3, $4)$ and the serotonergic neuron from the nucleus raphe magnus $(5,6)$. These substances play a significant role in the function of the cerebellum. However, it has been reported that dopamine (DA) or the dopaminergic neuron hardly exist in the cerebellum (7, 8). In previous studies $(9)$. we examined effects of CNS depressants or stimulants on the evoked potentials in the cat cerebellum. Caffeine, strychnine and picrotoxin significantly increased the evoked potentials on several areas of the cerebellar cortex, while pentobarbital sodium, meprobamate and morphine decreased them. In particular, chlorpromazine hydrochloride (CPZ) significantly increased the cerebellar potentials evoked by electrical stimulation of the peripheral nerve. It was suggested that these effects were due to the inhibitory influence of CPZ on the descending inhibitory system.

There are many descending inhibitory mechanisms such as the inhibitory system from the medulla oblongata-reticular formation (10), the noradrenergic system projecting from the nucleus reticularis paragigantocellularis via the nucleus reticularis lateralis (LRN) to the spinal cord (11), the serotonergic system projecting from the periaqueductal gray via the nucleus raphe 
magnus (12, 13), and the dopaminergic system from the substantia nigra $(14,15)$. LRN plays a significant role in the control of the input to the cerebellum as the precerebellar nucleus from the periphery to the cerebellum. CPZ has been utilized clinically as a major tranquilizer in the treatment of schizophrenia. psychoneurosis, etc. $(16,17)$. As a side effect, this drug also induces Parkinson's syndrome. which is a disorder of the motor system. Biochemically, CPZ depresses the release of norepinephrine (NE) from a preterminal site (18), and it is a DA or NE receptor antagonist (19, 20). When the mechanism of CPZ-induced enhancement of the cerebellar potentials is examined. consideration must be taken of the interaction between CPZ and NE or DA. We had a strong interest in this consideration in spite of the absence of DA or DA neuron in the cerebellum.

In the experiments reported here, we investigated the site of action and mechanisms of CPZ-induced enhancement of the cerebellar potentials using intact, decerebrated or spinal cat: and furthermore, we investigated the effects of microinjection of CPZ. DA or NE into the precerebellar nuclei.

\section{Materials and Methods}

Ninety-six adult cats of either sex, weighing $2.3-3.8 \mathrm{~kg}$, were used. The animals were anesthetized initially with ether and were fixed on a stereotaxic instrument (Narishige type). Tracheal, arterial and venous cannulas were inserted. The animals were artificially ventilated (25 revolutions per minute) following an intravenous injection of gallamine triethiodide. Xylocaine spray was frequently applied to the entire surgical area throughout the entire experiment. End-tidal $\mathrm{CO}_{2}$ was maintained at $3.5-4.0 \%$. Body temperature, monitored by a rectal probe, was maintained at $37-38^{\circ} \mathrm{C}$ by means of the heating pad. Arterial blood pressure, electrocardiogram (the second lead), and $\mathrm{O}_{2}$ saturation were recorded throughout the experiment.

The superficial radial nerve (SR) of the forelimb was dissected and cut at its peripheral end. The central part of the nerve end was placed on a bipolar stimulating electrode (platinum wires) with a $2 \mathrm{~mm}$ polar separation and was stimulated in a pool of warm liquid paraffin to prevent drying and then kept between $37-38^{\circ} \mathrm{C}$. A single rectangular pulse (duration: 0.1-0.2 msec, intensity: 3-4 V) was applied at a rate of 1 trial per $10 \mathrm{sec}$.

To record the potentials evoked on the cerebellar cortex, part of the occipital bone was removed to expose the vermis, which was then immersed in a pool of warm liquid paraffin. Recordings were made from the vermis using a monopolar silver ball electrode (diameter of $0.3 \mathrm{~mm}$ ).

Stainless steel concentric electrodes with a diameter of $0.6 \mathrm{~mm}$ (tip separation of $0.5 \mathrm{~mm}$ ) were inserted stereotaxically to stimulate the nucleus reticularis lateralis (LRN; $P$ : -9.5 . $\mathrm{L}: 4.0 . \mathrm{H}:-8.2)$ and nucleus olivaris inferior (ION: P: -9.5 . L: 2.5. $\mathrm{H}:-9.5$ ), located according to the atlas of Snider and Niemer (21). A single rectangular pulse of $0.1-0.2 \mathrm{msec}$ duration and 3-4 $\mathrm{V}$ intensity was applied to stimulate LRN or ION at a rate of 1 trial per 10 sec. Another preparation was to insert a microinjecting cannula into LRN or ION in order to inject CPZ, dopamine (DA) or NE. The reference electrode was located on the temporal muscle.

Spontaneous activities were recorded from the Purkinje neurons in the vermis, lobules VI and VII. For the study of spontaneous discharge, extracellular recordings of singleunit activity were obtained using micropipets filled with $3 \mathrm{M} \mathrm{KCl}$ solution (pontamine skyblue). The DC resistance was 5 to $10 \mathrm{M} \Omega$ Neurons were identified by means of anatomic location and through confirmation of the Purkinje spikes produced by the antidromic electrical stimulation of $10 N$ or the cerebellar white matter. Recordings of spontaneous firing in Purkinje cells were made following a stable condition of Purkinje cell firing for 5-10 min. Extracellular action potentials of the Purkinje cells were monitored on a medical oscilloscope (Model 311. San-ei Instrument Co., Ltd.) and converted to constant voltage pulses by the window discriminator. Spontaneous discharge rates of the Purkinje cells were measured using pulse density variation histograms obtained from a signal processor (Model 7T07, San-ei Instrument Co., Ltd.). 
In some experiments spinal cats and decerebrated cats (transected at the intracollicular level) were used. Laminectomy was performed between the $C_{1}$ and $C_{2}$ levels, and a silver ball electrode was placed on the surface of the dorso-lateral funiculi to record the potentials evoked following SR stimulation.

On termination of the experiments, $0.3 \mathrm{~mA}$ direct current was passed for $10 \mathrm{sec}$ through the electrodes from which evoked potentials had been recorded. The brain was removed and fixed in 10\% formalin and then sectioned serially at $50 \mu \mathrm{m}$ to verify histologically the points of electrode insertion.

In the above experiments, a stimulator (Model ME 6022. MEC) was used for the SR, LRN and ION stimulations. The evoked potentials were averaged by a signal processor (Model 7T07) via a dual beam oscilloscope and these recordings were made on an $X-Y$ recorder (Model WX 442, Watanabe). The upper side of the evoked potentials was expressed as a negative potential and the lower side as a positive one.

The amplitudes of the evoked potentials were measured from the baseline to the peak of a negative or positive wave. The time from the stimuli to the peak of the negative or positive component was termed as the peak time.

The drugs used in these experiments were chlorpromazine hydrochloride (Shionogi), dlnoradrenaline (Nakarai Chemicals, Ltd.) and dopamine (Nakarai Chemicals, Ltd.), which were dissolved in physiological saline solution.

The statistical significance of the data obtained was assessed using the two-tailed Student's $t$-test.

Details of "Materials and Methods" are summarized in Table 1 and Schema 1.

\section{Results}

\section{Effects of $\mathrm{CPZ}$ on Purkinje cell spontaneous discharge $(\mathrm{N}=15)$}

Table 1. Summary of "Materials and Methods"

I. Effects of intravenous CPZ

i) The evoked potentials

\begin{tabular}{|c|c|c|c|c|}
\hline \multirow{3}{*}{\multicolumn{2}{|c|}{ Stimulating site }} & Recording site & Preparation & Dose $(\mathrm{mg} / \mathrm{kg})$ \\
\hline & & Cerebellar cortex & Intact, Decerebrated & 7.5 \\
\hline & & LRN & ." $\quad$ " & $"$ \\
\hline \multirow{3}{*}{\multicolumn{2}{|c|}{ SR }} & ION & " & " \\
\hline & & Spinal cord & Spinal & " \\
\hline & & Cerebellar cortex & Intact (High frequency stimuli of LRN) & 2.0 \\
\hline & LRN or ION & Cerebellar cortex & Intact, Decerebrated. Spinal & 2.07 .5 \\
\hline \multirow[t]{2}{*}{ ii) } & \multicolumn{4}{|c|}{ Purkinje cell spontaneous discharge } \\
\hline & & Purkinje cell & Intact & $2.0 \quad 7.5$ \\
\hline
\end{tabular}

11. Effects of microinjections of CPZ, NE or DA on the cerebellar potential produced by the SR stimulation in intact cats

\begin{tabular}{|c|c|c|}
\hline Drug & Dose/body $(\mu \mathrm{g})$ & Microinjected site \\
\hline $\mathrm{CPZ}$ & 1 & $\begin{array}{l}\text { Bilateral. contralateral } \\
\text { or ipsilateral LRN }\end{array}$ \\
\hline & & Bilateral $10 \mathrm{~N}$ \\
\hline$N E$ & $10-30$ & $\begin{array}{l}\text { Ipsilateral or } \\
\text { contralateral LRN }\end{array}$ \\
\hline DA & $10-20$ & Ipsilateral LRN \\
\hline
\end{tabular}

SR: superficial radial nerve, LRN: nucleus reticularis lateralis, ION: nucleus olivaris inferior, CPZ: chlorpromazine. NE: norepinephrine, DA: dopamine. 

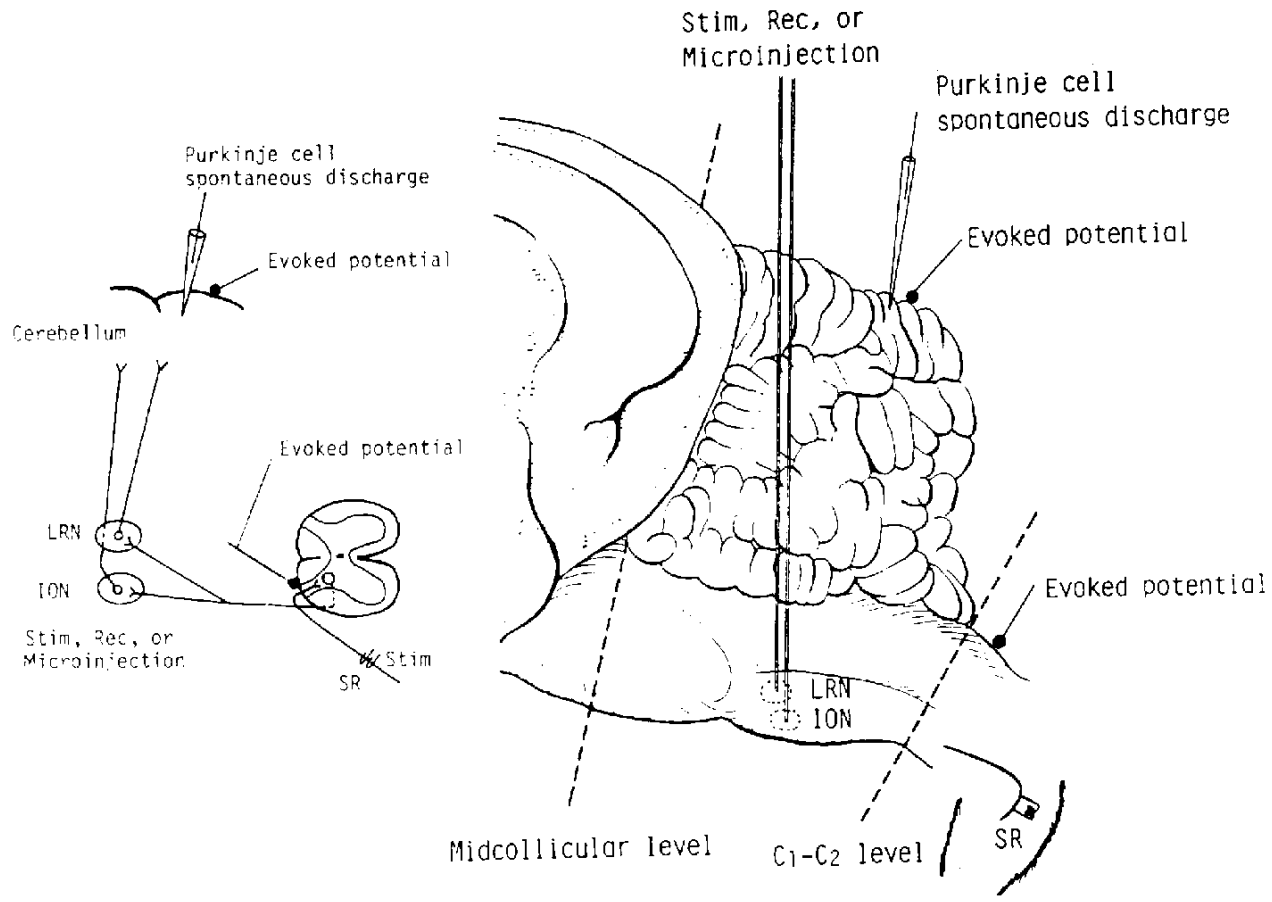

Schema 1. Diagramatic illustration of "Materials and Methods". The sketch is shown on the left, and the diagramatic illustration is shown on the right. Stim: stimulations, Rec: records. ION: nucleus olivaris inferior, LRN: nucleus reticularis lateralis, SR: superficial radial nerve.

Spontaneous discharge of fifteen Purkinje cells was recorded extracellularly from the vermis of the cerebellar cortex. The mean discharge rate was found to be $31 \pm 15$ spikes $/ \mathrm{sec}$. CPZ (2.0 mg/ $/ \mathrm{kg}$, i.v.) increased the spontaneous firing in 1 out of 5 cells, but this drug did not alter the firing in 4 out of 5 cells. CPZ (7.5 mg/kg, i.v.) inhibited the firing in 6 out of 10 cells. However, the firing was increased in 2 out of 10 cells; and in 2 out of 10 cells, it was not changed significantly (Table 2).

2. Potentials evoked on the spinal cord (dorsal surface) by SR stimulation, in spinal

\section{cats $(\mathrm{N}=5)$}

Electrical stimulation of SR evoked potentials consisting of the negative ( $N$ ) component alone, which had a peak time of $27.4 \pm 3.1$ msec, on the dorsal surface of the spinal cord. Peak times of the potentials evoked in this and the following experiments are shown in Table 3. CPZ produced little significant change in amplitude of the potentials evoked in spinal cats, at the early stage. Similarly, this drug produced a slight decrease of amplitude in intact cats (Table 4 and Fig. 1).

3. Potentials evoked on the cerebellar cortex by $S R$ stimulation in decerebrated cats $(N=5)$

Table 2. Effects of chlorpromazine hydrochloride on Purkinje cell spontaneous discharge

\begin{tabular}{|c|c|c|c|c|}
\hline \multirow{2}{*}{$\begin{array}{l}\text { Dose } \\
\mathrm{mg} / \mathrm{kg}\end{array}$} & \multirow{3}{*}{$\begin{array}{l}\text { Total cells } \\
\text { tested }\end{array}$} & \multicolumn{3}{|c|}{$\begin{array}{c}\text { Number of cells showing each type } \\
\text { of response (and } \% \text { ) }\end{array}$} \\
\hline & & Danracian & Erations & Naffon \\
\hline$\ldots \ldots$ & & & Excitation & No effect \\
\hline 2.0 & 5 & $0(0)$ & $1(20)$ & $4(80)$ \\
\hline 7.5 & 10 & $6(60)$ & $2(20)$ & $2(20)$ \\
\hline
\end{tabular}


Table 3. Time to peak of the potentials evoked by SR. LRN or ION stimulation on the cerebellar cortex, spinal cord, LRN or ION

\begin{tabular}{|c|c|c|c|c|c|}
\hline $\begin{array}{l}\text { Stimulating } \\
\text { site }\end{array}$ & $\begin{array}{l}\text { Recording } \\
\text { site }\end{array}$ & $\begin{array}{l}\text { Compo- } \\
\text { nent }\end{array}$ & Intact & $\begin{array}{c}\text { Decerebrated } \\
(\text { mean } \pm \text { S.D. }(\text { msec }))\end{array}$ & Spinal \\
\hline$S \bar{R}$ & Cerebellar cortex & $\begin{array}{l}N \\
P\end{array}$ & $\begin{array}{l}23.4 \pm 2.9 \\
45.2 \pm 2.4\end{array}$ & $\begin{array}{l}24.6 \pm 3.7 \\
44.7 \pm 5.8\end{array}$ & \\
\hline LRN & Cerebellar cortex & $\begin{array}{l}N \\
\rho\end{array}$ & $\begin{array}{l}14.7 \pm 4.2 \\
29.8 \pm 3.5\end{array}$ & $\begin{array}{l}12.4 \pm 2.5 \\
27.2 \pm 3.4\end{array}$ & $\begin{array}{l}11.3 \pm 0.7 \\
31.2 \pm 3.5\end{array}$ \\
\hline $10 N$ & Cerebellar cortex & $\begin{array}{l}N \\
P\end{array}$ & $\begin{array}{l}13.8 \pm 2.8 \\
34.6 \pm 4.2\end{array}$ & $\begin{array}{l}13.3 \pm 1.5 \\
30.2 \pm 4.2\end{array}$ & $\begin{array}{l}10.9 \pm 0.9 \\
29.6 \pm 3.2\end{array}$ \\
\hline $\mathrm{SR}$ & LRN & $\begin{array}{l}N \\
P\end{array}$ & $\begin{array}{l}21.8 \pm 2.3 \\
45.2 \pm 3.8\end{array}$ & $\begin{array}{l}24.1 \pm 3.1 \\
49.0 \pm 4.3\end{array}$ & \\
\hline SR & ION & $\begin{array}{l}N \\
P\end{array}$ & $\begin{array}{l}22.7 \pm 1.6 \\
48.6 \pm 6.4\end{array}$ & $\begin{array}{l}23.4 \pm 2.5 \\
47.2 \pm 5.2\end{array}$ & \\
\hline SR & Spinal cord & $N$ & & & $27.4 \pm 3.1$ \\
\hline
\end{tabular}

SR: superficial radial nerve, LRN: nucleus reticularis lateralis, ION: nucleus olivaris inferior, $N$ : negative, $P$ : positive.

Table 4. Effects of chlorpromazine hydrochloride on amplitudes of the potentials evoked by electrical stimulation of the superficial radial nerve, on the cerebellar cortex. precerebellar nuclei (LRN and ION). or the spinal cord (dorsal surface)

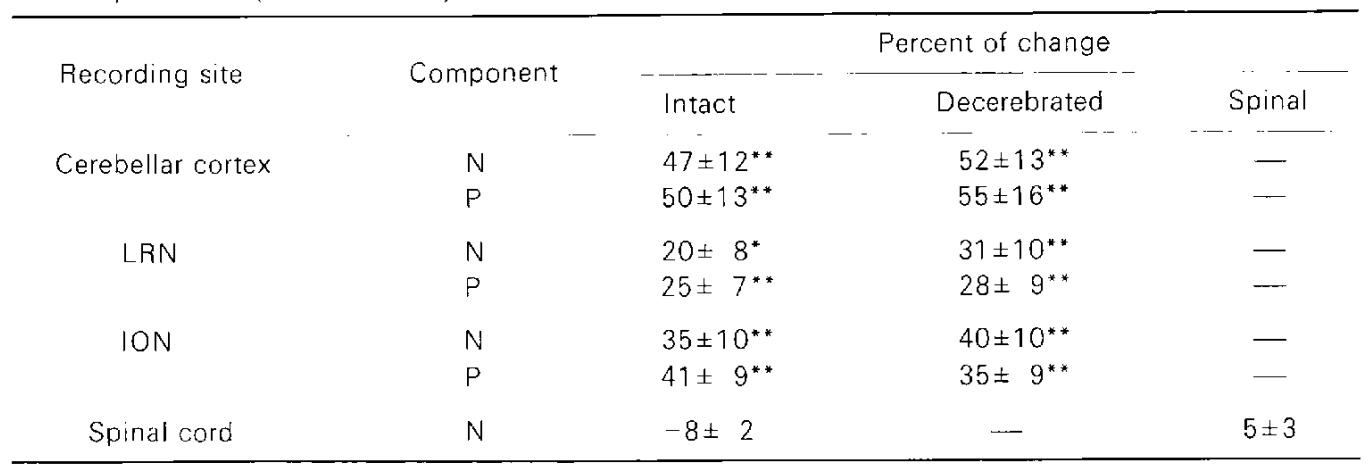

Each value indicates the percent change with respect to the control value (before treatment) and is shown as the mean \pm S.D. LRN: nucleus reticularis lateralis, ION: nucleus olivaris inferior, $N$ : negative, $P$ : positive, ${ }^{*} P<0.01,{ }^{*} P<0.001$.

CPZ maximally increased amplitudes of the $\mathrm{N}$ and positive (P) components at $30 \mathrm{~min}$ by $52 \pm 11 \%$ and $55 \pm 12 \%$, respectively (Table 4). Recovery occurred at about $180 \mathrm{~min}$. These results for decerebrated cats were almost similar to those for intact cats (Table 4 and Fig. 2).

\section{Potentials evoked by SR stimulation on the} LRN or ION, in intact or decerebrated cat

a. Intact cat $(\mathrm{N}=8)$ : $C P Z$ maximally increased at 15 min amplitudes of the $N$ and $P$ components by $20 \pm 8 \%$ and $25 \pm 7 \%$ in the
LRN, respectively, while CPZ maximally increased at $15 \mathrm{~min}$ amplitudes of both the components by $35 \pm 10 \%$ and $41 \pm 9 \%$ in the $10 \mathrm{~N}$, respectively (Table 4 ).

b. Decerebrated cat $(\mathrm{N}=8)$ : $C P Z$ maximally increased at 15-30 min amplitudes by $31 \pm 10 \%$ and $28 \pm 9 \%$ in the LRN, respectively. On the other hand, CPZ maximally increased at $15-30$ min amplitudes by $40 \pm 10 \%$ and $35 \pm 9 \%$ in the $10 \mathrm{~N}$, respectively. Recovery was seen at 150-180 min. These data are not given in the figure, but given in Table 4 . 
spinol cat

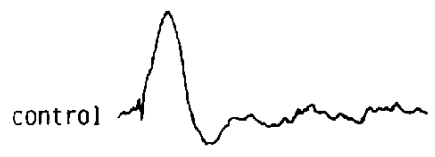

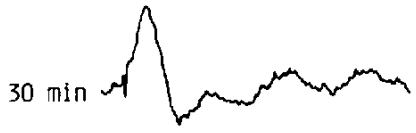

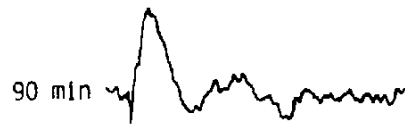<smiles>[Mg][Mg][Mg]</smiles>

intoct cot

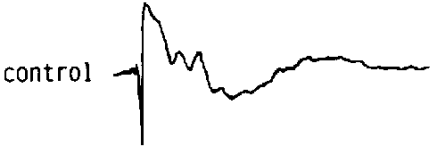

$30 \mathrm{~m} ! \mathrm{n}$
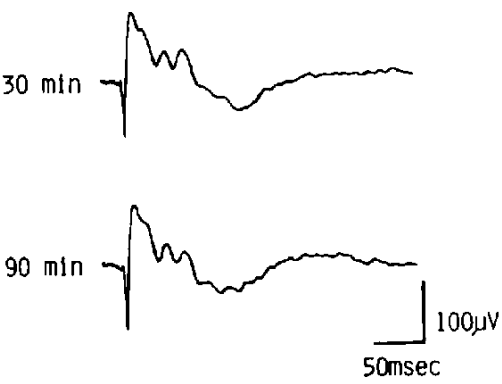

Fig. 1. Effects of chlorpromazine hydrochloride on the potentials of the dorsal surface of the spinal card evoked by the superficial radial nerve stimulation in the spinal or intact cat.
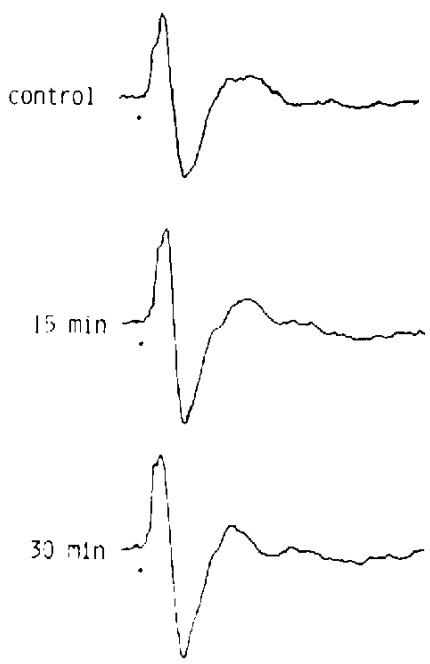
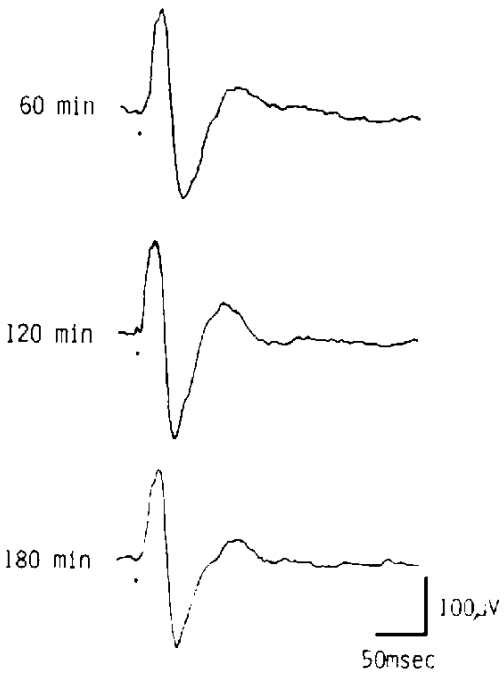

Fig. 2. Effects of chlorpromazine hydrochloride on the potentials of the cerebellar cortex evoked by superficial radial nerve stimulation in the intact cat. The timing of the stimulus is indicated by the dots.

These results in decerebrated cats were almost the same as those in intact cats (Table 4).

5. Potentials evoked on the cerebellar cortex by LRN or ION stimulation in intact, decerebrated or spinal cat

a. Intact cat $(\mathrm{N}=10)$ : $\mathrm{CPZ}(2.0$ and 7.5 $\mathrm{mg} / \mathrm{kg}$, i.v.) produced a dose-dependent decrease in amplitude of the potentials evoked by LRN stimulation. Namely, CPZ $(2.0 \mathrm{mg} /$ $\mathrm{kg}$ ) maximally decreased amplitudes of the $\mathrm{N}$ and $\mathrm{P}$ components at $30 \mathrm{~min}$ by $10 \pm 2 \%$ and $12 \pm 1 \%$, respectively, and $7.5 \mathrm{mg} / \mathrm{kg}$ of $\mathrm{CPZ}$ decreased amplitudes by $22 \pm 9 \%$ and $23 \pm 8 \%$, respectively. Similarly, CPZ produced a dosedependent decrease in amplitude of potentials evoked by $10 \mathrm{~N}$ stimulation. CPZ $(2.0 \mathrm{mg} / \mathrm{kg})$ maximally decreased amplitudes of both 
components at $30 \mathrm{~min}$, by $16 \pm 4 \%$ and $11 \pm 5 \%$, respectively, and $7.5 \mathrm{mg} / \mathrm{kg}$ of $\mathrm{CPZ}$ decreased amplitudes by $23 \pm 10 \%$ and $28 \pm 11 \%$, respectively. Recovery was observed to occur at 150-180 min. These data are given in Table 5 .

b. Decerebrated cat $(N=10)$ : CPZ (7.5 $\mathrm{mg} / \mathrm{kg}$, i.v.) maximally decreased amplitudes of the $N$ and $P$ components of the potentials evoked by LRN stimulation at $30 \mathrm{~min}$, by $33 \pm 8 \%$ and $29 \pm 9 \%$, respectively. CPZ also decreased amplitudes of both components of the potentials evoked by $10 \mathrm{~N}$ stimulation by $28 \pm 5 \%$ and $31 \pm 11 \%$, respectively, at 30 min. These results for decerebrated cats were similar to those for intact cats. Recovery was observed to occur at 150-180 min (Table 5).

c. Spinal cat $(\mathrm{N}=10)$ : CPZ $(7.5 \mathrm{mg} / \mathrm{kg}$, i.v.) maximally decreased amplitudes of the $N$ and $P$ components of the potentials evoked by LRN stimulation at $30 \mathrm{~min}$ by $19 \pm 7 \%$ and $30 \pm 10 \%$, respectively. CPZ also decreased amplitudes of both components of the potentials evoked by ION stimulation by $17 \pm 8 \%$ and $25 \pm 11 \%$ at $30 \mathrm{~min}$, respectively. Recovery was observed to occur at 150-180 min. These data for spinal cats were similar to those for intact and decerebrated cats (Table 5).

\section{Microinjection of $\mathrm{CPZ}$ into bilateral LRN or ION $(\mathrm{N}=10)$}

Electrical stimulation of the superficial radial nerve produced potentials consisting of $N$ and $P$ components, and which had peak times of $23.4 \pm 2.9 \mathrm{msec}$ and $45.2 \pm 2.4 \mathrm{msec}$ on the cerebellar cortex. We examined the effects of a few drugs on the amplitude of these components in the following experiments.

Microinjection of CPZ $(1 \mu \mathrm{g})$ into the bilateral LRN increased the amplitude of both of the cerebellar potentials by $35 \pm 10 \%$. On the other hand, microinjection of CPZ into the bilateral ION merely decreased the amplitude of the two components by $27 \pm 5 \%$. These data are given in Fig. 3 .

\section{Microinjection of $\mathrm{CPZ}$ or NE into con- tralateral LRN $(\mathrm{N}=5)$}

Microinjection of CPZ $(1 \mu \mathrm{g})$ or NE (10 "ug) hardly changed the amplitude of the cerebellar potentials (data not shown).

\section{Electrical stimulation at high frequency of} the ipsilateral LRN (N=5)

In order to activate the descending inhibitory system from the LRN, the ipsilateral LRN was stimulated at high frequency (duration: $100 \mu \mathrm{sec}$, intensity: $200 \mu \mathrm{A}$, frequency: $100 \mathrm{~Hz}, 1-2 \mathrm{~min}$ ). The resulting decrease in amplitudes of the $N$ and $P$ components were $36 \pm 11 \%$ and $14 \pm 2 \%$, respectively. When CPZ injected intravenously increased the amplitudes of both components. these were hardly changed by electrical stimulation at high frequency (Fig. 4).

9. Microinjection of CPZ into ipsilateral LRN $(N=5)$

Microinjection of CPZ (1 $\mu \mathrm{g}$ ) into the ipsilateral LRN enhanced $N$ and $P$ components of the cerebellar potentials by $24 \pm 8 \%$ and $16 \pm 3 \%$, respectively. These data are given in Fig. 5.

10. Microinjection of NE or DA into ipsilateral LRN $(\mathrm{N}=5)$

Table 5. Effects of chlorpromazine hydrochloride $(7.5 \mathrm{mg} / \mathrm{kg}, i . v$.) on amplitudes of the evoked potentials in the cat cerebellar cortex

\begin{tabular}{|c|c|c|c|c|}
\hline \multirow{2}{*}{$\begin{array}{l}\text { Stimulating } \\
\text { site }\end{array}$} & \multirow{2}{*}{ Component } & \multicolumn{3}{|c|}{ Percent of change } \\
\hline & & Intact & Decerebrated & Spinal \\
\hline \multirow[t]{2}{*}{ LRN } & $N$ & $-22 \pm 9^{*}$ & $-33 \pm 8^{* *}$ & $-19 \pm 7^{* *}$ \\
\hline & $\mathrm{P}$ & $-23 \pm 8^{* *}$ & $-29 \pm 9^{* *}$ & $-30 \pm 10^{* *}$ \\
\hline \multirow{2}{*}{ ION } & N & $-23 \pm 10^{*}$ & $-28 \pm 5^{* *}$ & $-17 \pm 8^{*}$ \\
\hline & $P$ & $-28 \pm 11^{* *}$ & $-31 \pm 11^{* *}$ & $-25 \pm 11 * *$ \\
\hline
\end{tabular}

Each value indicates the percent change with respect to the control value (before treatment) and is shown as the mean $\pm S$.D. LRN: nucleus reticularis lateralis. $10 N$ : nucleus olivaris inferior, $N$ : negative, $P$ : positive. ${ }^{*} \mathrm{P}<0.01,{ }^{*} \mathrm{P}<0.001,-$ : decreasing action. 

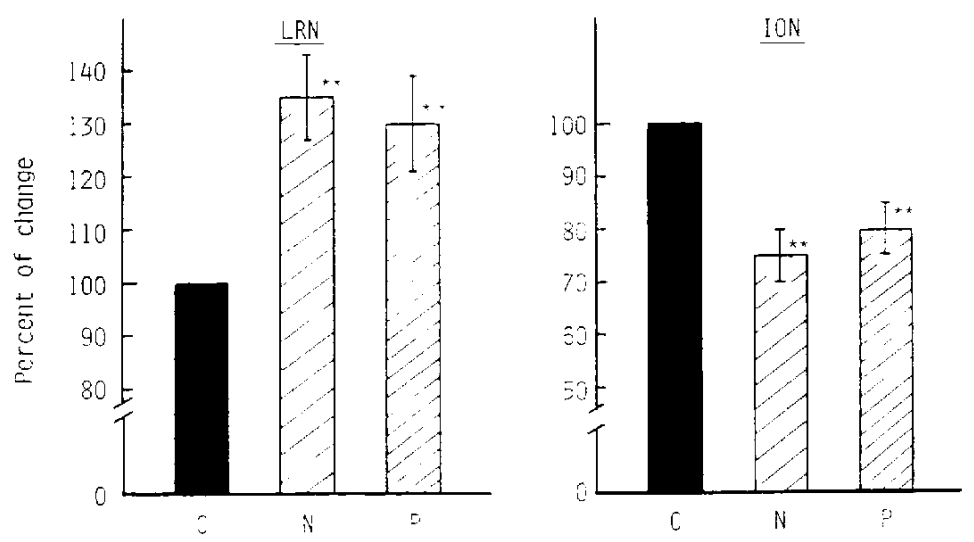

Fig. 3. Effects of microinjection of chlorpromazine $\mathrm{HCl}$ into the bilateral LRN or ION on amplitudes of the cerebellar potentials. Histograms show amplitudes of the $\mathrm{N}$ and $\mathrm{P}$ components after treatment, as percentage of the control. The control value (before treatment) is shown as $100 \%$. LRN: nucleus reticularis lateralis, $1 \mathrm{ON}$ : nucleus olivaris inferior, $\mathrm{C}$ : control, $\mathrm{N}$ : negative, $\mathrm{P}$ : positive, ${ }^{* *} \mathrm{P}<0.001$.

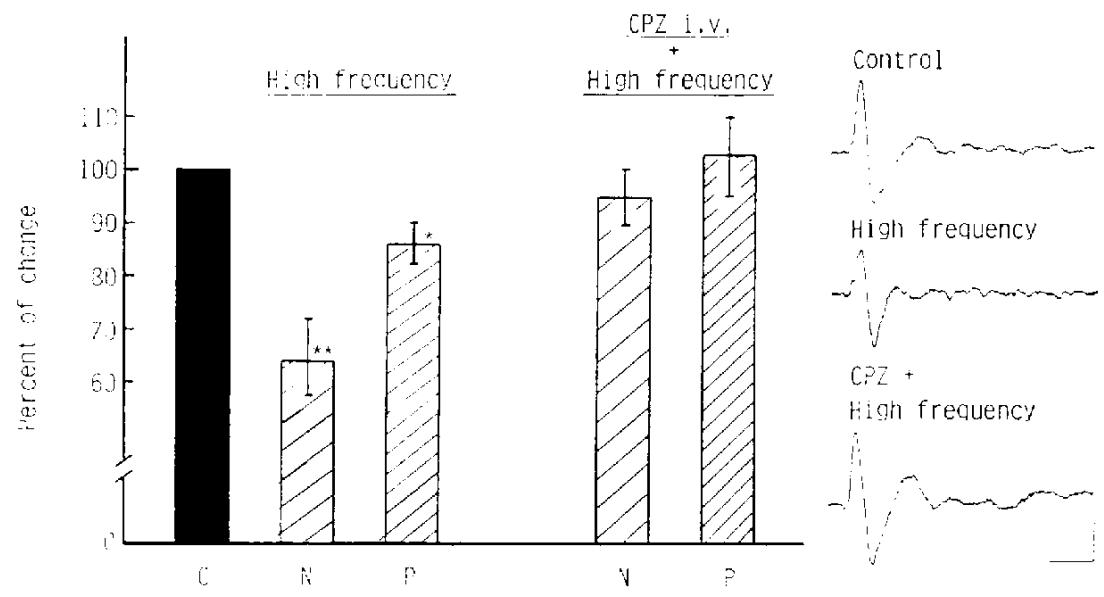

Fig. 4. Effects of the electrical stimulation at high frequency of ipsilateral LRN on the potentials evaked by the peripheral nerve stimulation on the cerebellar cortex. Histograms show amplitudes of the $\mathrm{N}$ or $\mathrm{P}$ components after treatment as a percentage of the control. Data for electrical stimulation at high frequency $(100 \mu \mathrm{sec}, 200 \mu \mathrm{A}, 100 \mathrm{~Hz}, 1-2 \mathrm{~min}$ ) are shown on the left, and data for stimulation after pretreatment with intravenous chlorpromazine $\mathrm{HCl}$ are shown on the right. Right side indicates practical evoked potentials produced by the peripheral nerve stimulation on the cerebeliar cortex (Vertical scale $=100 \mu \mathrm{V}$, horizontal scale $=50 \mathrm{msec})$. C: control, $\mathrm{N}$ : negative, $\mathrm{P}$ : positive, ${ }^{*} \mathrm{P}<0.01,{ }^{* *} \mathrm{P}<0.001$.

Microinjection of NE $(10-30 \mu \mathrm{g})$ into the LRN decreased significantly $\mathrm{N}$ and $\mathrm{P}$ components by $27 \pm 7 \%$ and $15 \pm 4 \%$, respectively. in a dose-dependent manner. However. microinjection of DA $(10-20 \mu \mathrm{g})$ decreased the amplitudes of $N$ and $P$ components by $28 \pm 8 \%$ and $5 \pm 2 \%$ (Fig. 5)

11. Microinjection of $\mathrm{DA}$ and $\mathrm{CPZ}$ into ipsilateral LRN $(\mathrm{N}=5)$
When pretreatment of microinjected DA $(10 \mu \mathrm{g})$ decreased the amplitude of the two components, microinjection of CPZ (1 $\mu \mathrm{g})$ into the LRN reversed this action of DA. namely increasing the $N$ component by $15 \pm 7 \%$ and the $P$ component by $17 \pm 4 \%$. while after pretreatment with CPZ $(1 / \mathrm{gg})$. microinjection of DA $(10 \mu \mathrm{g})$ into ipsilateral LRN failed to change the amplitude of either 

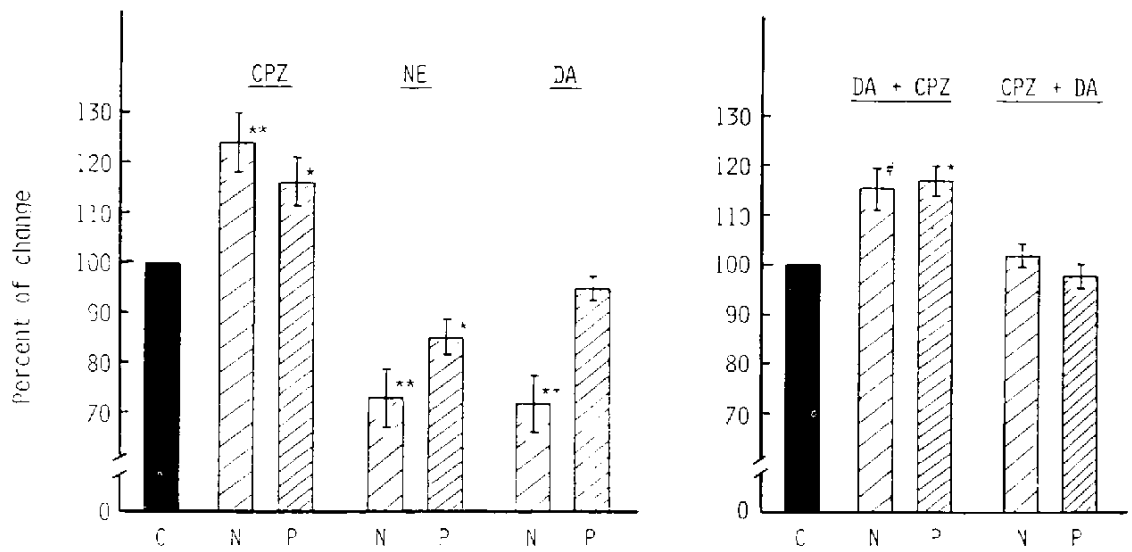

Fig. 5. Effects of microinjection of chlorpromazine, dopamine or norepinephrine into ipsilateral LRN on the cerebellar potentials. Histograms show amplitudes of the $\mathrm{N}$ or $\mathrm{P}$ components after treatment, as percentages of the control. The control value (before treatment) is shown as $100 \%$. The figure on the left shows data for microinjection of chlorpromazine. dopamine or norepinephrine: the figure on the right shows data for microinjection of chlorpromazine after dopamine pretreatment and for microinjection of dopamine after chlorpromazine pretreatment. $C$ : control, $N$ : negative, $P$ : positive, $" P<0.05, * P<0.01$, **P $<0.001$.

component. In other words, effects of DA were antagonized by pretreatment with CPZ. These data are given in Fig. 5 .

\section{Discussion}

In a previous study (9), we examined the effects of several drugs on the evoked potentials in the cat cerebellar cortex. In particular, we observed that CPZ significantly increased the input from the periphery to the cerebellum in intact cats and suggested that this effect was due to the inhibitory influence of CPZ on the descending inhibitory system.

In the present work, we investigated in detail the site and mechanism of action in CPZ-induced enhancement of cerebellar evoked potentials.

With regard to the $\mathrm{CPZ}$-induced enhancement, we considered the following four hypotheses: 1) direct action to the cerebellum. 2) direct action to the spinal cord. 3) effects of CPZ on the cerebrum, or 4 ) indirect action to other areas.

At first, as it was thought that CPZinduced enhancement may be due to the direct action of CPZ to the cerebellum itself, we studied the effect of CPZ on the Purkinje cell spontaneous discharge. Pertaining to the effect of CPZ on the Purkinje cell discharge, it was reported that CPZ facilitated the cell firing in a dose-dependent manner in rats (22) or that the firing was not changed by microelectrophoretical CPZ in cats (23). We recognized that lower doses of $\mathrm{CPZ}$ did not change the firing in $80 \%$ of the Purkinje cells tested, and higher doses depressed the discharge in $60 \%$ of the cells tested and did not change the firing in $20 \%$. Thus, it was suggested that CPZ-induced enhancement may be due not to a direct action of CPZ to the cerebellum itself, but to the effect of this drug on a certain area in the pathway to the cerebellum.

Secondly, we examined effects of CPZ on the spinal cord, pathways from the periphery to the cerebellum, using the spinal cat. Regarding the effects of $\mathrm{CPZ}$ on the spinal cord. there were a few reports of its direct action on the spinal level $(24,25)$. On the other hand, CPZ did not affect monosynaptic and polysynaptic spinal reflex in spinal cats: but in intact cats, it was suggested that these effects of CPZ were concerned with actions of this drug on the excitatory area and the descending inhibitory area of the medulla oblongata (26). We recognized that $\mathrm{CPZ}$ hardly changed the evoked potentials produced by the peripheral nerve stimulation on the dorsal surface of the spinal cord in spinal and intact cats. Thus, it cannot be concluded 
that CPZ-induced enhancement was concerned with the spinal cord alone.

Thirdly, it was demonstrated that effects of $C P Z$ in the spinal cord were affected from the supraspinal level (26) and that CPZ enhanced the afterdischarge of the amygdala in the limbic system $(27,28)$. Therefore, CPZinduced enhancement may be concerned with the effect of CPZ on the cerebrum. In order to determine the influence of CPZ on the supraspinal level, the action of $C P Z$ was also investigated using the decerebrated cat (transected at the midcollicular level). CPZ increased the evoked potentials produced by the peripheral nerve stimulation in the precerebellar nuclei (LRN and ION) and the cerebellar cortex. These effects of CPZ were similar to those in the intact cat. Therefore, it was suggested that CPZ-induced enhancement was, at least partly, involved in the area (perhaps the medulla oblongata) below the midcollicular transected level.

Then, we also examined the following experiments regarding the precerebellar nuclei (LRN and ION) that exist in the medulla oblongata, from the periphery to the cerebellum. It has been reported that there are an inhibitory system descending from the medullary reticular formation to the spinal cord (10) and a noradrenergic inhibitory system descending from the nucleus reticularis gigantocellularis or nucleus reticularis paragigantocellularis via the LRN to the spinal cord (11). In addition, it has been demonstrated that if the brainstem, in particular the inhibitory area of the medulla oblongata, is depressed, the dorsal spinocerebellar tract neurons projecting directly to the cerebellum are liberated from the descending inhibitory system (29). We therefore microinjected CPZ into the bilateral $\angle R N$ or ION: these nuclei are also precerebellar nuclei between the periphery and the cerebellum. CPZ enhanced the cerebellar potentials only in the case of microinjection into not the ION but into the LRN. LRN receives its input of noradrenergic neurons from the nucleus locus coeruleus (3, 4). Therefore, in order to investigate the interaction between CPZ and DA or NE, and furthermore, the participation of ipsilateral or contralateral LRN, we microinjected CPZ,
DA or NE into each lateral side of the LRN. Microinjection of CPZ or NE into the contralateral LRN hardly changed the cerebellar potentials. On the other hand. microinjection of NE or DA into the ipsilateral LRN decreased the cerebellar potentials significantly, and microinjecting CPZ enhanced them. Thus, it was considered that the neuron controlling the activity of LRN is related to the catecholaminergic system. Namely, we thought that microinjected DA or NE activates catecholamine receptors in the LRN, so the descending inhibitory mechanism from the ipsilateral LRN may act ipsilaterally on a pathway from the periphery to the cerebellum.

$C P Z$ is known as a DA or NE receptor antagonist $(19,20)$. We also used DA and $\mathrm{CPZ}$ together to examine the interaction between CPZ and NE or DA. When pretreatment of microinjected DA into LRN decreased the cerebellar potentials, posttreatment of CPZ. increased them significantly. However, after pretreatment with $\mathrm{CPZ}$, microinjection of $D A$ into the LRN hardly changed the cerebellar potentials. It was thought that DA could not combine with the DA receptors since CPZ blocked catecholamine (maybe dopamine) receptors in the LRN.

In order to activate the descending inhibitory system from the ipsilateral LRN, LRN was stimulated at high frequency. Electrical stimulation at high frequency of the LRN decreased the cerebellar potentials significantly. After the cerebellar potentials were increased by intravenous injection of $C P Z$, they remained unchanged by subsequent high frequency stimulation. Thus, it was clear that the descending inhibitory system from the ipsilateral LRN might act on the pathway from the periphery to the cerebellum.

In conclusion, we suggest that CPZ (intravenous administration)-induced enhancement of the cerebellar potentials evoked by the peripheral stimulation may be due to depression of the descending inhibitory system, resulting from $C P Z$-induced blockage of the DA receptors of the ipsilateral LRN and $C P Z$-induced blockage of NE receptors of the spinal level. which received the descending inhibitory system from the ipsilateral LRN. 
Acknowledgment: We thank Di. Yuji Maruyama (Nippon-Kayaku Co.. Ltd., Research Laboratory) for revising this manuscript.

\section{References}

1 Okamoto, K.: Neurotransmitter candidates acting on cerebellar Purkinje cells. Japan. J. Neuropsychopharmacol. 3, 893-902 (1981) (in Japanese)

2 Okamoto, K. and Sakai, Y.: Inhibitory actions of taurocyamine, hypotaurine, homotaurine, taurine and GABA on spike discharge of Purkinje cells, and localization of sensitive sites, in guinea-pig cerebellar slices. Brain Res. 206, 371-386 (1981)

3 Siggins, G.R., Hoffer, B.J. and Bloom, F.E.: Activation of a central noradrenergic projection to cerebellum. Nature 233, 481-483 (1971)

4 Hoffer, B.J., Siggins, G.R., Oliver, A.P. and Bloom, F.E.: Activation of the pathway from locus coeruleus to rat cerebellar Purkinje neurons: pharmacological evidence of noradrenergic inhibition. J. Pharmacol. Exp. Ther. 184, 553-569 (1973)

5 Hökfelt, T. and Fuxe, K.: Cerebellar monoamine nerve terminals, a new type of afferent fibers to the cortex cerebelli. Exp. Brain Res. 9, 63-72 (1969)

6 Chan-Palay, V.: Serotonin afferent from raphe nuclei to the cerebellum in animals. Exp. Brain Res., Supp. 1, 20-25 (1976)

7 Ungerstedt, $U$ :: On the anatomy, pharmacology and function of the nigrostriatal dopamine system. Section I: Stereotaxic mapping of the monoamine pathways in the rat brain. Acta Physiol. Scand., Supp. 367, 1-48 (1971)

8 Simon, H., LeMoal, M. and Calas, A.: Efferents and afferents of the ventral tegmental-A 10 region studied after local injection of $\left[{ }^{3} \mathrm{H}\right]$ leucine and horseradish peroxidase. Brain Res. $178,17-40(1979)$

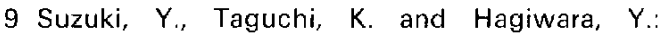
influences of drugs on evoked potentials in the cat cerebellum: I. Effects of CNS depressants and stimulants on the cerebeliar afferent pathways. Japan. J. Pharmacol. 32, 457-468 (1982)

10 Lindsley, D.B., Schreiner, L.H. and Magoun, H.W.: An electromyographic study of spasticity. J. Neurophysiol. 12, 197-205 (1949)

11 Takagi, H.: Distribution of opioid peptides and kyotorphin in the brain and their analgesic mechanisms. Seitai no Kagaku 32, 417-424 (1981) (in Japanese)

12 Hökfelt, T., Ljungdahl, A., Steinbusch, H., Verhofstad, A., Nilsson, G., Brodin, E., Pernow, B. and Goldstein, $M_{\text {: }}$ Immunohistochemical evidence of substance P-like immunoreactivity in some 5-hydıxytryptamine containing neurons in the rat central nervous system. Neuroscience 3. 517-538 (1978)

13 Björklund, A.J., Emson, P.C., Gilbert, R.F.T. and Skagerberg, G.: Further evidence for the possible coexistence of 5-hydroxytryptamine and substance $P$ in medullary raphe neurons of rat brain. Br. J. Pharmacol. 66, 112-113 (1979)

14 Fleetwood-Walker, S.M. and Coote, J.H.: Contribution of noradrenaline-. dopamine- and adrenaline-containing axons to the innervation of different region of the spinal cord of the cat. Brain Res. 206, 95-106 (1981)

15 Fleetwood-Walker, S.M. and Hope, P.J.: A selective antinociceptive effect of the diencephalic dopamine-containing cell group. A 11. on dorsal horn neurons in the rat. $J$. Physiol. (Lond) 364, 47P (1985)

16 Goldstein, L. and Stoltzfus, N.W.: Psychoactive drug-induced changes of interhemispheric $E E G$ amplitude relationship. Agents Actions 3/2, 124-132 (1973)

17 Itil, T.H.: Electroencephalography and pharmecopsychiatry dinical psychopharmacology. Mod. Probl. Pharmacopsychiatry 1, 163-194 (1968)

18 Seeman, P. and Lee, T.: Antipsychotic drugs: direct correlation between clinical potency and presynaptic action on dopamine neurons. Science 188, 1217-1219 (1975)

19 Andën, N.E., Buther, S.G., Corrodi, H., Fuxe, K. and Ungerstedt, $U .:$ Receptor activity and turnover of dopamine and noradrenaline after neuroleptics. Eur. J. Pharmacol. 11, 303-314 (1970)

20 Wilson, M.C. and Schuster, C.R.: The effects of chlorpromazine on psychomotor stimulant selfadministration in the rhesus monkey. Psychopharmacologia (Beriin) 26, 115-126 (1972)

21 Snider, R.S. and Niemer, W.T.: A Stereotaxic Atlas of the Cat Brain. The University of Chicago Press. Chicago (1961)

22 Marwaha, J., Hoffer, B.J., Geller, H.M. and Freedman, R.: Electrophysiologic interactions of antipsychotic drugs with central noradrenergic pathways. Psychopharmacology (Berlin) 74, 126-133 (1981)

23 Maruyama, S.: Interaction between possible transmitters and butyrophenones applied microelectrophoretically in the cerebellum and basal ganglia of the cat. 2 nd report: Effects of some phenothiazines on the Purkinje cells of the cerebellum. Japan. J. Pharmacol. 25, Supp. 79P (1975) 
24 Carp, J.S. and Anderson, R.J.: Modification of the spinal cord transmission by an interaction of chlorpromazine and phenytoin. J. Pharmacol. Exp. Ther. 216, 270-274 (1981)

25 Strahlendorf, J.C., Strahlendorf, H.K., Kingsley, R.E., Gintautas, J. and Barnes, C.D.: Facilitation of the lumbar monosynaptic reflexes by locus coeruleus stimulation. Neuropharmacology 19. 225-230 (1979)

26 Takaori, S.: The site of action of chlorpromazine on the central nervous system of cats. Folia Pharmacol. Japon. 54, 7-20 (1958) (in Japanese)
27 Preston, J.B.: Effect of chlorpromazine on the central nervous system of the cat; a possible neural basis for action. J. Pharmacol. Exp. Ther. $118,100-115$ (1956)

28 Watanabe, S., Nishi, H. and Ueki, S.: Electroencephalographic effects of hydroxyzine hydrochloride (Atarax) in rabbits. Folia Pharmacol. Japon. 70, 19-37 (1973) (Abs. in English)

29 Kubota, S., Amano, K., Kitamura, K. and Popple, R.E.: Differences of behaviour of DSCT neurons in decerebrate and barbiturate anesthetized cats. Brain and Nerve 30, 387-391 (1978) (in Japanese) 